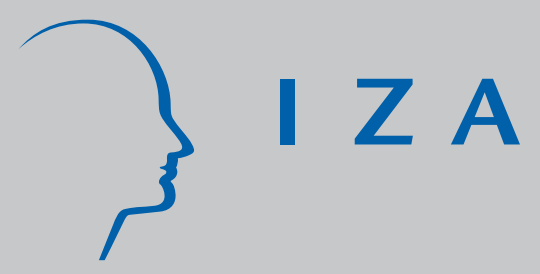

IZA DP No. 445

Informational Cascades and Decision to Migrate

Gil S. Epstein

March 2002 


\title{
Informational Cascades and Decision to Migrate
}

\author{
Gil S. Epstein \\ Bar-Ilan University, Israel, CEPR, London \\ and IZA, Bonn
}

\section{Discussion Paper No. 445 \\ March 2002}

\author{
IZA \\ P.O. Box 7240 \\ D-53072 Bonn \\ Germany \\ Tel.: +49-228-3894-0 \\ Fax: +49-228-3894-210 \\ Email: iza@iza.org
}

This Discussion Paper is issued within the framework of IZA's research area Mobility and Flexibility of Labor. Any opinions expressed here are those of the author(s) and not those of the institute. Research disseminated by IZA may include views on policy, but the institute itself takes no institutional policy positions.

The Institute for the Study of Labor (IZA) in Bonn is a local and virtual international research center and a place of communication between science, politics and business. IZA is an independent, nonprofit limited liability company (Gesellschaft mit beschränkter Haftung) supported by the Deutsche Post AG. The center is associated with the University of Bonn and offers a stimulating research environment through its research networks, research support, and visitors and doctoral programs. IZA engages in (i) original and internationally competitive research in all fields of labor economics, (ii) development of policy concepts, and (iii) dissemination of research results and concepts to the interested public. The current research program deals with (1) mobility and flexibility of labor, (2) internationalization of labor markets, (3) the welfare state and labor markets, (4) labor markets in transition countries, (5) the future of labor, (6) evaluation of labor market policies and projects and (7) general labor economics.

IZA Discussion Papers often represent preliminary work and are circulated to encourage discussion. Citation of such a paper should account for its provisional character. A revised version may be available on the IZA website (www.iza.org) or directly from the author. 
IZA Discussion Paper No. 445

March 2002

\section{ABSTRACT}

\section{Informational Cascades and Decision to Migrate}

We introduce the idea that informational cascades can explain the observed regularity that emigrants from the same locations also tend to choose the same foreign locations. Thus informational cascades generate herd behavior. Herd behavior is compared with the network externalities explanation of the same phenomenon. The relation between social tensions and herd behavior is observed when local populations are xenophobic.

JEL Classification: F22, J61

Keywords: $\quad$ Migration, informational cascades, herd behavior, xenophobia, network externalities

Gil S. Epstein

Department of Economics

Bar-llan University

52900 Ramat-Gan, Israel

Tel.: +972-3-531 8937

Fax: +972-3-535 3180

Email: epsteig@mail.biu.ac.il

\footnotetext{
* We acknowledge the comments of Barry Chiswick, Don DeVoretz, Ira Gang, Arye Hillman, Louka Katseli, Francisco Rivera-Batiz, Oded Stark, Thomas Straubhaar, Yoram Weiss and Klaus Zimmermann.
} 


\section{Introduction}

Consider yourself living in a small town in a low-income country, and you have decided to emigrate. Where would you go? You might prefer a country because of language familiarity. That may leave you with a number of alternatives. Or you may choose a foreign location because of the presence of network externalities. The network externalities in the foreign location are the consequence of the prior presence of people from your own home community. You may have a relative, or a friend of the family, in the foreign location. Or least the name and address of somebody who knows your family and who will treat you sympathetically and assist with housing and finding a job, and perhaps in explaining the rules of neighborhood. ${ }^{1}$ As With language proficiency, in all likelihood a number of foreign locations can provide such network externalities. The presence of network externalities is then not sufficient to provide a basis for a decision. A choice remains to be made from among the available alternatives where network externalities are present.

From among the alternatives where there are benefits of network externalities, one location would be revealed as the best choice, if full information were available about local conditions. If such full information is not available, a choice is made under conditions of uncertainty. If you have imperfect information, which decision rule would you adopt? In the face of uncertainty, a common decision rule is to randomize, but here you confront an indivisible location decision. You may not know all that much about life in that location. You observe, however, that other people who are like you have recently been favoring this location. You might have a personal feeling that the location people have been choosing is not the best from among the available alternatives. You might, however, decide to discount this feeling based on your private information, and to proceed on the assumption that others have been making decisions based on better information than you have. That is, you may take the position that so many other people cannot be wrong. If you behave in this way and discount private information or your feelings to follow the decisions of others, you are adopting a decision rule that gives rise to herd behavior.

\footnotetext{
${ }^{1}$ See Gottlieb 1987, Grossman 1989, Marks 1989, Church and King 1993 and Chiswick and Miller 1996.
} 
In this paper we set out a formal framework that introduces informational cascades that generate a theory of herd behavior together with the theory of migration. In the model emigrants may have some private information but are imperfectly informed about the attributes of alternative foreign locations, and they observe previous emigrants' decisions. Behavior is rational on the supposition by impending emigrants that previous emigrants had information that they do not have. The outcome is that emigrants discount private information and duplicate a location that previous emigrants have been observed to choose. ${ }^{2}$ The consequence is immigrant clustering in foreign locations, but based on a decision rule that does not internalize all true information.

Since individuals are discounting private information that may be accurate and making decisions based on the perception that other people's information is accurate when others are likewise discounting private information, we can have no expectation that outcomes will have desirable properties.

The paper proceeds as follows. We first set out the model of herd behavior in the following section, and then analyze herd behavior together with network externalities.

\section{The Model}

\section{A. The background}

We consider a country where potential emigrants are identical other than in age and information, and are uncertain about conditions in the rest of the world. We do not wish to attribute aspects of behavior to risk aversion, and so take emigrants to be risk neutral (although we realize in practice they may not be). An emigrant's utility $U($.$) is increasing in income, and in other parameters that we shall subsequently$ introduce. From among the different alternative foreign locations for emigration

\footnotetext{
${ }^{2}$ The theory of information cascades or herd effects has been applied to the explanation of behavior in a number of contexts. See Scharfstein and Stein (1990), Banerjee (1992), Bikhchandani, Hirshleifer and Welch (1992).
} 
(legal or illegal), one location objectively offers better conditions than others. Emigrants do not know the identity of this best foreign location. They have a uniform prior over foreign locations. An individual may decide not to emigrate, which is encompassed by viewing one of the locational options as the home country. We now demonstrate the formal structure of emigration decisions that follow herd behavior using in turn one- and two-signal models.

\section{B. A one-signal model}

Imperfect private information provides a signal, with probability $p$, regarding the identity of the best foreign country. With probability $q$, the signal providing this private information is true. A signal if false does not provide information regarding the true signal. Also, to simplify, we assume that, for two locations, $q>0.5$ (or $q>$ $1 / m$ where for $m$ foreign locations). Otherwise there is a better chance of choosing the preferred country by randomizing than by using the information provided by the signal.

Emigration decisions made sequentially, with people contemplating emigration at a given age or stage in their lives. In the sequential decision process, people of different ages make decisions regarding immigration at different times. Someone may have received a signal, and he or she can also observe the behavior of previous emigrants. Potential emigrants cannot however observe the information signal that was the basis for previous emigrants' decisions. While potential new immigrants know the choices made by past emigrants, they do not have to know the latters' position in the queue. Given the information available, each person chooses a location to which to emigrate. The structure of the game and Bayesian rationality are common knowledge. Three assumptions govern individuals' actions:

(i) A person who does not receive a signal and observes that everybody else has chosen to stay home, will also choose not to emigrate.

(ii) Someone who is indifferent between following his or her own signal and copying someone else's choice will follow his or her own signal. 
(iii) Someone who is indifferent between copying previous emigrants' decisions will make a decision by randomizing with equal probabilities assigned to the different alternatives.

These assumptions, which minimize the likelihood of herd behavior, give rise to the following different possibilities:

The first person making a decision: This person fails to receive a signal with probability ( $1-p)$ and receives a signal with probability $p$. In the first case, by assumption $a$, he will not emigrate. In the second case, he will follow his signal, and will emigrate. The probability that emigration is to the correct country is $q$.

The second person: If person 2 has received no signal, then she follows person 1 . If only person 2 has a signal, she of course will follow her signal. If the two people have different signals (person 1 chose to emigrate and thus had a signal), then person 2 is indifferent between following her own signal and copying person 1, as the both persons' signals have the same probability of being true. In this case, by assumption $b$, person 2 will follow her own signal.

The third person: If neither of the two previous persons chose to emigrate, this means that neither received a signal. Person 3 will copy them if and only if he does not receive a signal, and otherwise will follow the signal he receives.

If one of the previous persons chose not to emigrate and the other chose to emigrate, person 1 did not receive a signal and person 2 did receive a signal. If person 3 then receives a signal that indicates emigration to the country to which the second person has emigrated, person 3 will join the second emigrant. Otherwise, if a signal different to that of person 2 is received, person 3 follows his own signal. If persons 1 and 2 have chosen to emigrate to different countries, and person 3 does have a signal, then person 3 will base his emigration decision on his own private information as conveyed by the signal he receives. This can be shown formally in the following way:

Assume that person 1 emigrated to country $j$, that person 2 emigrated to country $k$, and person 3 has a signal to emigrate to country $j$. Using the Bayesian rule, 
person 3 can calculate the probability that the true signal is $j$ out of $m$ possible countries:

$$
\operatorname{Pr}(j \mid j, k, j)=\frac{p^{3} q^{2}(1-q) 1 / m}{\operatorname{Pr}(k, j, j)}
$$

In the same way, person 3 could calculate the probability that the true signal is $k$ :

$$
\operatorname{Pr}(k \mid j, k, j)=\frac{p^{3} q(1-q)^{2} 1 / m}{\operatorname{Pr}(k, j, j)}
$$

For $q>0.5$,

$$
\operatorname{Pr}(j \mid j, k, j)>\operatorname{Pr}(k \mid j, k, j)
$$

from which it follows that person 3 will choose to follow his own signal.

There is one further possibility: that the first two persons choose to emigrate to country $j$ and the third person receives a signal to emigrate to country $\mathrm{k}$. This last possibility brings us to a general proposition. First, however, to simplify, we add the following assumption:

Assumption $d: \quad q(1-q)>0.5\left(\frac{1-p}{p}\right)^{2}$

That is, we place a lower bound on the probability that an individual receives a signal. The assumption is relaxed in proposition 2.

Proposition 1 : If at a point in time the number of emigrants in country $\mathrm{j}$ is greater than emigrants in all the other countries by at least two persons, then from that time on, all persons, regardless of their signal, will emigrate to country $\mathrm{j}$, and so we have herd behavior.

\footnotetext{
${ }^{3}$ By definition, the probability $q$ is normalized in regard to the two different locations.
} 
For proof, see the appendix. The proposition is true for any number of countries, as the choice is always whether to follow one's signal or to follow the herd, that is, the problem is always a binomial decision.

In order for herd behavior to occur after a difference between two individuals, we require a bound on the probability that a signal is received:

$$
p^{2} q(1-q)>0.5(1-p)^{2}
$$

Thus, as $q$ increases, in order for herd behavior to occur, a higher value of $p$ is required. As the probability of receiving a signal decreases, more emigrants are required to create herd behavior, and we can conclude that:

Proposition 2: For a given probability $q$ that a signal is true, as the probability that an individual receives a signal $p$ decreases, the number of emigrants required to evoke herd effect increases.

A person who has chosen to emigrate does not immediately know the quality of life in the new location. Suppose that a person has emigrated, and after some time a clustering of immigrants occurs in a different country. As the emigrant continues to confront uncertainty regarding future income and the future quality or standard of life in the new country, he or she once again calculates the probability regarding the best country. The propositions above indicate that such a person will decide to leave the country of initial choice and join the herd.

\section{An illustration}

We now present an illustration. We have established that if the first two persons emigrate to the same location, all subsequent persons will emigrate to this 
same location. The probability that the two first persons will emigrate to the same location is (where we assume that $j$ is the best location):

$$
\begin{aligned}
& \operatorname{Pr}(\text { clusteringinonecountry })= \\
& \operatorname{Pr}(\text { clustring incountry } j \mid j \text { istherightcountry }) \operatorname{Pr}(j \text { istherightcountry })+ \\
& \operatorname{Pr}(\text { clustringincountry } j \mid k \text { istherightcountry }) \operatorname{Pr}(k \text { istherightcountry })+ \\
& \operatorname{Pr}(\text { clustring incountryk } \mid k \text { istherightcountry }) \operatorname{Pr}(k \text { istherightcountry })+ \\
& \operatorname{Pr}(\text { clustringincountry } k \mid j \text { istherightcountry }) \operatorname{Pr}(j \text { istherightcountry })
\end{aligned}
$$

Using the values of the different probabilities, we obtain:

$$
\begin{aligned}
& \operatorname{Pr}(\text { clusteringinonecountry })= \\
& \left(p^{2} q^{2}+p(1-p) q\right) 1+\left(p^{2}(1-q)^{2}+p(1-p)(1-q)\right) 0+ \\
& \left(p^{2} q^{2}+p(1-p) q\right) 0+\left(p^{2}(1-q)^{2}+p(1-p)(1-q)\right) 1= \\
& p^{2} q^{2}+p(1-p) q+p^{2}(1-q)^{2}+p(1-p)(1-q)
\end{aligned}
$$

In the case where $q=0.51$ and $p=1$ (all people obtain a signal), we calculate this probability to be 0.5002 . More generally, as $q$ increases, for any $p$, the probability of clustering in one of the countries increases:

$$
\frac{\partial \operatorname{Pr}(\text { clustering })}{\partial q}=2 p^{2}(2 q-1)>0
$$

Herd behavior thus occurs with positive probability. Simple Markovian reasoning tells us that, with an infinite population size, the probability of any event occurring is one. Thus, if the population size is infinite, after some point in time, with probability one, there will be clustering of immigrants in one location.

\section{Multiple signaling}

In a multiple-signaling version of the model, a person can receive two types of signals: a general signal, a specific signal from previous emigrants, and also can observe the behavior of previous emigrants. Again, he or she cannot however observe

\footnotetext{
${ }^{4}$ For a similar result, see Bikhchandani, Hirshleifer and Welch (1992).
} 
the signal that was the basis of the decisions of past emigrants, and, given the information available, each person proceeds to choose a country of emigration. We retain assumptions $a, b, c$ and $d$ and add the assumption: (e) individuals value a specific signal from former emigrants, $q_{i}$, more than a general signal, $q$, i.e. $q \leq q_{i} \quad \forall q^{5}$

Notice that a person can receive a specific signal to go to a particular country only if there has been a prior emigrant to that country. An immigrant who receives opposite general and specific signals must determine which to follow. It is clear that the probability that an individual will choose to emigrate against his specific signal is smaller than against his general signal. However, the presence of a greater number of emigrants already located in the host country against the specific signal increases the probability that the emigrant follows the herd. We summarize the results in the following proposition:

Proposition 3: With multiple signals, if two initial persons have emigrated to the same country, subsequent emigrants copy them regardless of their own signals; otherwise, herd behavior will occur when the difference between the number of emigrants in two countries is large enough; and as the probability that a person's own signal is true increases, the difference decreases between the number of emigrants in alternative locations required for herd behavior.

\footnotetext{
${ }^{5}$ One of the key determinants of the location of immigration is past colonial relationships. The general signal can be interrupted accordingly. We can view the specific signal as evidence that an immigrant has gone to the wrong country and chooses another location at the next period. Here seeing the individual change his/her decision can be seen as a specific signal telling the individual not to immigrate to a location. The signal is not true with probability one as it is not clear why the emigrant changed his decision, and it may well be that the location may not suit him while this is the correct choice for other emigrants.

${ }^{6}$ The proof is available on request.
} 


\section{Network externalities}

As we observed in the introduction, herd behavior is conceptually different and distinguishable from migration that is motivated by network externalities (see also the concluding section). There is also no reason why herd effects and network externalities should not be simultaneously present to influence emigration location decisions. When there is simultaneous presence, there is also interaction. In this section we place net externalities within our model of herd behavior and show the nature of the interactions between the two phenomena.

To introduce network externalities, we follow the representation of Carrington, Detragiache, and Vishwanath (1996). We denote by the cost of emigration of individual $t$ by $\quad c_{t}=c\left(M_{t-1}, h\right)$ and the number of migrants already settled in the new location by $M_{t-1}$. The latter is also a measure of the magnitude of the positive network externality. $h \in H$ indicates personal characteristics affecting the cost of migration, for example, age, family, social status assets, etc. $F(h)$ denotes the measure of workers of type less than or equal to $h$. A potential emigrant calculates the present discounted value of income for staying at home and emigrating. The present value of income of someone who emigrated at time $t$ is

$$
V\left(M_{t}, h\right)=w\left(M_{t}\right)+\delta \max \left[V\left(M_{t+1}, h\right), \bar{V}\left(M_{t+1}, h\right)\right] .
$$

The present value of income of a person who decides not to emigrate at time $t$ is:

$$
\bar{V}\left(M_{t}, h\right)=\bar{w}\left(M_{t}\right)+\delta \max \left[V\left(M_{t+1}, h\right)-c\left(M_{t}, h\right), \bar{V}\left(M_{t+1}, h\right)\right]
$$

where the wage $w($.$) decreases with the number of immigrants M_{t .} \bar{w}($.$) is the wage in$ the home country, which is an increasing function of the number of people who emigrate. Hence, from the time that the number of emigrants is large enough, all emigrants of type $h^{\prime}$ and above immigrate to the new destination. With endogenous moving costs, the impetus for emigration develops gradually over time. Emigration, once it begins, gains momentum, and the number of people who migrate can well increase even as differences in wages between the country of emigration and 
immigration decline. In a network-externalities model, costs of relocation thus decrease with the number of immigrants, which encourages more emigration, and leads to immigrant clustering -- but some immigrant clustering must already have been present to provide the externalities.

These network externalities can be embedded in our model of herd behavior. Consider a demand-supply framework in the host country. Denote demand for immigrants in country $j$ by $q_{j}{ }^{D}=b_{0}-b_{1} w_{j}$ where $q_{j}$ denotes the number of immigrants and $w_{j}$ is the wage. The supply function is $q_{j}{ }^{s}=a_{0}+a_{1} w_{j}+N_{j}$, where $N_{j}$ is the number of immigrants into the country. In equilibrium $q_{j}{ }^{D}=q_{j}{ }^{s}$ and the equilibrium wage is:

$$
w_{j}=\frac{b_{0}-a_{0}-N_{j}}{a_{1}+b_{1}} \text {. }
$$

It is clear that, as the number of migrants increases, the wages decreases. Let $w_{j}>w_{k}$ for all $k \neq j$. Denote utility of a representative emigrant by $\mathrm{U}(C, N, L)=C^{\delta_{1}} N^{\delta_{2}} L^{\delta_{3}}$ where $C$ is consumption and $L$ is the size of the local population, with $\delta_{1}, \delta_{2}, \delta_{3}<1$. Externalities are reflected in the size of the local population and in the number of immigrants. All income is spent on consumption, so that $C=w_{j}$, and

$$
\mathrm{U}(C, N, L)=\left(\frac{b_{0}-a_{0}-N}{a_{1}+b_{1}}\right)^{\delta_{1}} N^{\delta_{2}} L^{\delta_{3}}
$$

The condition for utility to be increased by more immigrants is

$$
N<\left(b_{0}-a_{0}\right) \frac{\delta_{2}}{\delta_{1}+\delta_{2}}=N_{0}
$$

\footnotetext{
7 See also Choi (1997).

${ }^{6}$ See Brezis and Krugman (1996) for an argument that this is so in the short run, but not necessarily in the long run.
} 
which shows that the wage and consumption decrease as immigration increases, but that the loss in utility is offset by network-externality benefits.

Let one person emigrate to a designated country when a second person receives a positive signal indicating emigration to a different country. If this latter person chooses to follow the first migrant, then she knows that all successors will follow, for informational and payoff reasons (herd behavior and positive externalities). If she chooses the other country, there is a positive probability that she will end up alone. So, while she may think that the basic payoff or utility from moving to the alternative country is as good as for the first country, the awareness of the positive network payoff will induce her to choose the location chosen by this first emigrant. Herd behavior is therefore more pronounced than when externalities are absent, and with high probability the first emigrant will be followed by everyone.

In disregarding network externalities to focus on herd behavior, we took it to be the case that an emigrant had no information regarding expected utility, and received signals regarding the probability that a particular country offered the best location. ${ }^{10}$ In the presence of beneficial externalities, the utility from emigration to a country depends on: (1) the number of immigrants who have previously immigrated and (2) how many people will immigrate in the future. So even if the wage in a country is relatively low, the positive externalities may make that country an attractive location.

For example: suppose $n$ people have emigrated to country $j$ and one person has emigrated to country number $k$, and that utility of an immigrant in country $j$ is higher than that of an immigrant in country $k$. It could however be that if $n$ immigrants had immigrated to country $k$ and one immigrant to country number $j$, utility in country $k$ would have been higher than in country $j$ (if $n$ immigrants had immigrated to that country). With herd behavior, the probability that a signal received by an individual is

\footnotetext{
${ }^{9}$ Notice that $\left(b_{0}-a_{0}\right)>0$ and $\frac{\delta_{2}}{\delta_{1}+\delta_{2}}<1$.

${ }^{10}$ If an individual were able to calculate expected utility in the foreign country, the combined herd effects and positive externalities could be easily established.
} 
true is a function of both the number of previous immigrants that have immigrated to the same country and the number of immigrants that have chosen other countries.

We can define the probability in the following way: Suppose an individual has received a signal that country $j$ is best, and has to choose between country $j$ and country $k$. Given the number of individuals who have already emigrated to country $j$ and $k$, the probability that this signal is true is given by:

$$
q_{j}^{\prime}(.)=q_{j}^{\prime}\left(\frac{n_{j}}{n_{k}}\right) \text { while } \frac{q_{j}^{\prime}\left(\frac{n_{j}}{n_{k}}\right)}{\partial\left(\frac{n_{j}}{n_{k}}\right)}>0
$$

The probability $q_{j}^{\prime}($.$) represents the normalized probability that the right thing to do$ is follow the signal. Thus $q^{\prime}{ }_{j}($.$) is a function of all the information, i.e., the number$ of emigrants who have already emigrated to the different countries, and the basic probability that the signal is true $q\left(q_{j}^{\prime}(\right.$.$) is calculated in a similar way as in (1).$

Thus, the benefits from network externalities influence the probability that a signal is true via the relative number of immigrants who previously emigrated to the different countries. When we now recompute the probabilities of section 2 , we find that herd effects are more pronounced because of the externalities, and we conclude:

Proposition 7: The probability of herd behavior increases in the presence of positive externalities.

As argued above, given that the immigrant is already in the host country then he prefers that the total number of immigrants will be equal to $N_{0}=\left(b_{0}-a_{0}\right) \frac{\delta_{2}}{\delta_{1}+\delta_{2}}$ - However when this individual makes his decision wither to immigrate to this county, he will compare the expected utility from the different countries and chose the one with the highest value. We therefore may see immigrants deciding to immigrate 
to a country that the number of immigrants has already exceeded $N_{0}$. Thus, the probability that an individual will chose to immigrate to a country that the number of immigrants already exceeding $N_{0}$ is positive. This probability however, will decrease as the number of immigrants already in the host country increases. We conclude,

Proposition 8: Given network externalities, the probability an individual will immigrate to a certain country has an inverse $U$ shape relationship with regard to the number of immigrants already in the host country.

Herd effects are less pronounced when externalities are negative. ${ }^{11}$ Consider a general signal received by an individual to move to country $j$ rather than country $k$. The probability associated with this signal increases with the relative number of immigrants who already chose $j$, only if the total number of past emigrants is less than a bound, determined by the number at which negative externalities set in. Denote this number by $m_{j}$. Then:

$$
\begin{gathered}
\qquad q_{j}^{\prime}(.)=q_{j}^{\prime}\left(\frac{n_{j}}{n_{k}}\right) \\
\text { while } \frac{q^{\prime}\left(\frac{n_{j}}{n_{k}}\right)}{\partial\left(\frac{n_{j}}{n_{k}}\right)}>0 \text { for } n_{j}<m_{j} \text { and } n_{k}<m_{k}
\end{gathered}
$$

and

$$
\frac{q^{\prime}\left(\frac{n_{j}}{n_{k}}\right)}{\partial\left(\frac{n_{j}}{n_{k}}\right)}<0 \text { for } n_{j}>m_{j} \text { and } n_{k}<m_{k}
$$

\footnotetext{
${ }^{11}$ When disadvantageous externalities are present, incentives arise to move to new locations, in the course of which individuals tend to reveal private information -- as they will only emigrate to another location if warranted by private information.
} 
The probability that the private signal is true is independent of the number of emigrants who previously chose a country.

If disadvantageous externalities are present, incentives arise to move to new locations, in the course of which individuals tend to reveal private information -- as they will only migrate to another location if warranted by private information. Informational herd effects are therefore less pronounced in the case of negative externalities.

A migrant may move to a country and find out that the marginal positive effect of the externalities is lower than the marginal negative effect of the wage. In other words, the stock of immigrants that have migrated to this host country has exceeded $N_{0}$. A migrants that is leaving in this host country, where the stock of migrants is higher than $N_{0}$ will now send negative specific signals to his home country people who are thinking about migrating to that country. The signals will be saying not to migrate to where he migrated. The local population at the home country receives these negative signals. However, the population at home knows that a lot of individuals have migrated to this country and may even receive other information that this place is the right place to which to immigrate. An individual that has to make the decision will weigh the information he received: the stock of previous individuals that migrated to that country (and to other countries), the general information he received while observing the flow of migrants and the negative information he received from the migrants that have already immigrated to that country. This individual knows that there is a positive probability that the information he received from the migrants in the host country is true for them as they do not want other migrants to join them. However, it may be optimal for the migrant to join them even if there are negative signals. In order for the individual to follow the flow (herd), the proportion of negative signals relative to the stock of migrants must fall. Thus if the stock of immigrants is sufficiently large in the host country, the new migrants may continue to follow the herd even though the network externalities are negative. 


\section{Concluding remarks}

Our purpose in this paper has been to draw attention to informational cascades and herd behavior as an influence on emigration location. Herd behavior offers an information perspective on why emigrants from the same location make the same foreign relocation decision.

Herd behavior complements network externalities in explaining foreign location decisions. Network externalities may be necessary, but not sufficient, to explain the foreign locational choice, since a number of alternative locations may all offer network externalities. Herd effects can explain which of the alternatives offering network externalities is chosen.

There are a number of additional dimensions to differences between network externalities and herd effect explanations for choice of emigrants' destinations. Positive network externalities tell a story of efficiency through the internalized benefits provided by the externalities. There are no mistakes. Herd behavior introduces the possibility of economic inefficiency through the discounting of accurate private information. Also a prior critical presence of emigrants with the same cultural background or from the same location is required for network externalities. This is not a requisite of a herd-effects explanation of foreign location for an emigration decision.

When the population of prior immigrants in a foreign location is small, network externalities are of course not present. Still, emigration decisions are made, generally under conditions of uncertainty. In such cases, we can only look to herd effects to explain initial immigrant clustering.

After the immigrant population reaches a particular size, relations can become more impersonal, and the arrival of someone from "back home" may not evoke the same feeling of responsibility and benevolence. Network externalities can therefore be subject to diseconomies of size of the immigrant population. After a sufficiently long presence, a local individualistic culture can take hold ("let the new arrival work hard and succeed by his own merits like I did"). Thus, after a certain number of 
immigrants, it may be beneficial for the emigrant to join a different network. Herd behavior will lead immigrants to continue coming to the same location when network externalities no longer justify this decision

Network externalities appear to be more important than herd effects for illegal immigrants, or when legal immigrants convert to illegality (see Epstein et al, 1998 and Epstein, 2001), because of the greater need of illegal immigrants for surreptitious existence and protection. Herd behavior can however be expected to diminish in significance as prospective emigrants have access to more sophisticated and accurate information about conditions in foreign locations, since more weight is then placed by people on private information.

Migrants are many times wanted in the host country however, influencing migrants to emigrate to the home country may cause a herd of others entering the host country. Thus the country may receive more than what it wished for. This has a more complex perspective of national preferences or xenophobia regarding immigrant composition 13

Empirically we can distinguish between network externalities and herd effects in stock and flow terms. If the flow of emigrants to different locations is related to the prior of stock of emigrants, we can infer network externalities are important. If the flow of emigrants is related to prior flows, herd effects are important.

\footnotetext{
12 Oded Stark (1995) has suggested that adverse selection (high productivity immigrants do not wish low-productive people to immigrate) limits the number of immigrants who can benefit from network externalities, and has proposed that prior immigrants therefore have reason to bribe others to stay home. Herd effects can lead to the same conclusion.
}

${ }^{13}$ The national preferences reflect electoral outcomes, political popularity, and mass expression in various countries. Local indigenous populations have expressed discontent and uneasiness, and in cases have also become violent, because of immigration issues. In some European countries, parts of the local population have expressed anti-immigration preferences through the polls. Political parties taking explicit anti-immigrant positions have found significant support in France, Austria, Switzerland, and the eastern regions of Germany. In Norway, when foreign presence is low, immigration has been a major electoral issue, and also in Denmark, where the foreign presence is higher. There has also been antiimmigration sentiment in Sweden. Xenophobia and national ethnic preference have been found outside of Europe, in Indonesia, for example, the Chinese population suffered in the vast pogroms of the 1960s and again in 1998. Indians were expelled from Uganda. In Fiji the indigenous population revoked democracy when they became a minority. 


\section{Appendix: Proof of proposition 1}

Denote by $\operatorname{Pr}(j \mid n j,(n-2) k, k)$ the probability that $j$ is the best country to which to emigrate, and let it be observed that $n$ individuals have immigrated to country $j$; (n-2) to country $k$; and an individual receives a signal to immigrate to country $k$. First consider the case of three persons: The two first persons have immigrated to country $j$ and person 3 has received a signal to immigrate to country $k$. Given assumptions $a$ and $b$, it is clear that the first person has received a signal to immigrate to country $j$ and the second person either did not receive a signal or received a signal to immigrate to country $j$. We can calculate the probability that $j(k)$ is the true signal. Using the Bayesian rule, given this information, the probability that the $j$ signal is true out of $m$ possible countries is:

$$
\operatorname{Pr}(j \mid 2 j, 0 k, k)=\frac{\left(p^{3} q^{2}(1-q)+p^{2}(1-p) q(1-q)\right) 1 / m}{\operatorname{Pr}(k, j, j)}
$$

In the same way we calculate the probability that $k$ is the true signal:

$$
\operatorname{Pr}(k \mid 2 j, 0 k, k)=\frac{\left(p^{3} q(1-q)^{2}+p^{2}(1-p) q(1-q)\right) / / m}{\operatorname{Pr}(k, j, j)}
$$

Given that $q>0.5, \operatorname{Pr}(k \mid 2 j, 0 k, k)<\operatorname{Pr}(j \mid 2 j, 0 k, k)$.

Since the decision is between two different locations (out of a larger set of locations), the conditional probability for $q$ is thus greater than 0.5 . Given that the conditional probability $q>0.5$ it holds that $\operatorname{Pr}(k \mid 2 j, 0 k, k)<\operatorname{Pr}(j \mid 2 j, 0 k, k)$.

We now consider the case where one person has immigrated to country $k$; three persons have immigrated to country $j$, and the fifth person has received a signal to immigrate to country $k$. Necessarily, the first individual received a signal for $j$ and the second receives a signal to country $k$. The third individual receives a signal for $j$ or randomly selects $j$. The fourth individual does not receive a signal for $k$. Finally, the fifth individual receives a signal for $k$. So, 


$$
\operatorname{Pr}(3 j, 1 k, k \mid j)=p q p(1-q)(p q+0.5(1-p))(p q+(1-p)) p(1-q)
$$

Likewise,

$$
\operatorname{Pr}(3 j, 1 k, k \mid k)=p q p(1-q)(p(1-q)+0.5(1-p))(p(1-q)+(1-p)) p q
$$

By Bayes' rule,

$$
\operatorname{Pr}(j \mid 3 j, 1 k, k)=\frac{\operatorname{Pr}(3 j, 1 k, k \mid j)}{\operatorname{Pr}(3 j, 1 k, k \mid j)+\operatorname{Pr}(3 j, 1 k, k \mid k)}
$$

which is larger than $\operatorname{Pr}(k \mid 3 j, 1 k, k)=1-\operatorname{Pr}(j \mid 3 j, 1 k, k)$ if and only if

$\operatorname{Pr}(j \mid 3 j, 1 k, k)>0.5$, which is equivalent to $\operatorname{Pr}(j \mid 3 j, 1 k, k)>\operatorname{Pr}(k \mid 3 j, 1 k, k)$. We now see that $\operatorname{Pr}(j \mid 3 j, 1 k, k)>\operatorname{Pr}(k \mid 3 j, 1 k, k)$ if and only if

$$
(p q+0.5(1-p))(p q+(1-p)) p(1-q)>(p(1-q)+0.5(1-p))(p(1-q)+(1-p)) p q
$$

Thus (23) holds if and only if

$$
p^{2} q(1-q)>0.5(1-p)^{2}
$$

(24) holds by assumption d. The rest of the proof is by induction. We have shown that the herd behavior occurs in the two cases. Assume that the country that has the largest number of immigrants, country $j$, has $n((n-1))$ immigrants Denote by $k$ the country with the second largest number of immigrants, with (n-2) $((n-3))$ immigrants. We have shown that herd behavior holds true for $n=2$ and $n=3$. Assume that it holds for $n$ and $n-1$. We will show that it holds for $n+1$ and $n+2$. Assuming that:

$$
\operatorname{Pr}(j \mid n j,(n-2) k, k)>\operatorname{Pr}(k \mid n j,(n-2) k, k)
$$

and

$$
\operatorname{Pr}(j \mid(n-1) j,(n-3) k, k) \quad>\quad \operatorname{Pr}(k \mid(n-1) j,(n-3) k, k)
$$

Our aim is to show that 


$$
\operatorname{Pr}(j \mid(n+1) j,(n-1) k, k)>\operatorname{Pr}(k \mid(n+1) j,(n-1) k, k)
$$

and

$$
\operatorname{Pr}(j \mid(n+2) j, n k, k)>\operatorname{Pr}(k \mid(n+2) j, n k, k)
$$

Using Bayes' rule, (27) and (28) hold if and only if

$$
\operatorname{Pr}((n+1) j,(n-1) k, k \mid j)>\operatorname{Pr}((n+1) j,(n-1) k, k \mid k)
$$

and

$$
\operatorname{Pr}((n+2) j, n k, k \mid j)>\operatorname{Pr}((n+2) j, n k, k \mid k)
$$

Let us first consider the case where $n+1$ people have emigrated to country $j, n-1$ people have emigrated to country $k$, and an individual has received a signal to emigrate to country $k:((n+1) j,(n-1) k, k)$. Given (25) and (26) it is at most the case that: $n-1$ people have emigrated to country $j$ and $n-1$ people have immigrated to country $k:((n-1) j,(n-1) k)$, otherwise we would have had a herd behavior when the event $(n j,(n-2) k)$ occurred and the event $((n+1) j,(n-1) k, k)$ would have never occurred:

$$
\begin{gathered}
\operatorname{Pr}((n+1) j,(n-1) k, k \mid j)=\operatorname{Pr}((n-1) j,(n-1) k) \operatorname{Pr}(3 j, 1 k, k \mid j) \frac{1}{p^{2} q(1-q)} \\
\text { and } \\
\operatorname{Pr}((n+1) j,(n-1) k, k \mid k)=\operatorname{Pr}((n-1) j,(n-1) k) \operatorname{Pr}(3 j, 1 k, k \mid k) \frac{1}{p^{2} q(1-q)}
\end{gathered}
$$

where $\operatorname{Pr}((n-1) j,(n-1) k \mid j)=\operatorname{Pr}((n-1) j,(n-1) k \mid k)=\operatorname{Pr}((n-1) j,(n-1) k)$.

Given (23) and (24), it is clear that (31) holds. In the same way we prove (28). 


\section{References}

Banerjee A.V. (1992) “A Simple Model of Herd Behavior”, Quarterly Journal of Economics, 107(3), 797-817.

Bikhchandani, S., Hirshleifer, D. and Welch, I. (1992) "A Theory of Fads, Fashion, Custom, and Culture Change as Informational Cascades", Journal of Political Economy, Vol. 100 (5), pp. 992-1026.

Brezis, E.S. and Krugman, P.R. (1996), "Immigration, Investment, and Real Wages", Journal of Population Economics, 9(1), 83-93.

Carrington, W.J., Detragiache, E. and Vishwanath, T. (1996), "Migration with Endogenous Moving Costs" American Economic Review, 86(4), 909-30.

Chiswick, B.R. and Miller, P.M (1996), "Ethnic Networks and Language Proficiency among Immigrants", Journal of Population Economics, 9(1), 19-35.

Choi, P. (1997) "Herd Behavior, the "Penguin Effect" and the Suppression of Informational Diffusion: An Analysis of Informational Externalities and Payoff Interdependency", Rand Journal of Economics, Vol. 28(3), pp. 407-425.

Church, J. and King, I. (1983), "Bilingualism and Network Externalities", Canadian Journal of Economics; 26(2), 337-45.

Corak, Miles (2001), "Are the Kids All Right? Integration Mobility and Child Well-Being in Canada." In Keith Banting, Andrew Sharpe, and France St-Hilaire (editors). The Review of Economic and Social Performance, The Longest Decade; Canada in the 1990s. Montreal: McGill - Queen`s Press

Epstein, G.S., (2001), "Labor Market Interactions Between Legal and Illegal Immigrants", Review of Development Economics, forthcoming

Epstein, G.S., Hillman A.L., and Weiss, A. (1998), "Creating Illegal Immigrants," Journal of Population Economics, 12, 3-21.

Gottlieb, P. (1987), Making Their Own Way: Shorthorn Blacks' Migration to Pittsburgh, 1916-30, Urbana: University of Illinois Press.

Gul, F. and Lundholm, R. (1995), "Endogenous Timing and the Clustering of Agents' Decisions" Journal of Political Economy, 103, 1039-66 
Grossman, J. R. (1989), Land and Hope: Chicago, Black Southerners, and the Great Migration, Chicago, University of Chicago Press.

King, S.P. (1995), "Search with Free-Riders", Journal of Economic Behavior and Organization, 26(2), 253-71.

Marks, C. (1989), Farewell -We're Good and Gone: The Great Black Migration, Bloomington, Indian University Press.

Scharfstein, D.S. and Stein, J. C. (1990), "Herd Behavior and Investment", American Economic Review, 80(3), 465-79.

Stark, O. (1995), Altruism and Beyond: An Economic Analysis of Transfers and Exchange Within Families and Groups, Cambridge: Cambridge University Press. 


\section{IZA Discussion Papers}

$\begin{array}{ll}\text { No. } & \text { Author(s) } \\ 430 & \begin{array}{l}\text { J. Schwarze } \\ \text { M. Härpfer }\end{array} \\ & \\ 431 & \begin{array}{l}\text { M. Fertig } \\ \text { C. M. Schmidt }\end{array} \\ & \text { E. Tekin } \\ 432 & \text { J. D. Angrist } \\ 433 & \text { A. D. Kugler }\end{array}$

434
A. D. Kugler

G. S. Epstein M. E. Ward
A. Kunze

M. Fertig
A. Voicu

G. Fella

P. Manzini

M. Mariotti

$$
\begin{aligned}
& \text { G. Bertola } \\
& \text { S. Hochguertel } \\
& \text { W. Koeniger }
\end{aligned}
$$

Dealer Pricing of Consumer Credit

From Severance Pay to Self-Insurance: Effects Colombia

Perceived Income, Promotion and Incentive

The Evolution of the Early Career Gender Wage 1 Gap

Evaluating Immigration Policy Potentials and Limitations

Employment Dynamics in the Romanian Labor Market: A Markov Chain Monte Carlo Approach

Does Divorce Law Matter?

Earnings Inequality and Transition: A Regional 4 Analysis of Poland

Estimating the Effect of Income on Health and Mortality Using Lottery Prizes as Exogenous Source of Variation in Income

Identifying Functional Labour Market Areas in 1 New Zealand: A Reconnaissance Study using Travel-to-Work Data

Benefit Entitlement and the Labor Market:

$02 / 02$

$02 / 02$

$02 / 02$

02/02

02/02

$02 / 02$

$02 / 02$
Area

02/02

02/02

$02 / 02$ Evidence from a Large-Scale Policy Change

Informational Cascades and Decision to Migrate 